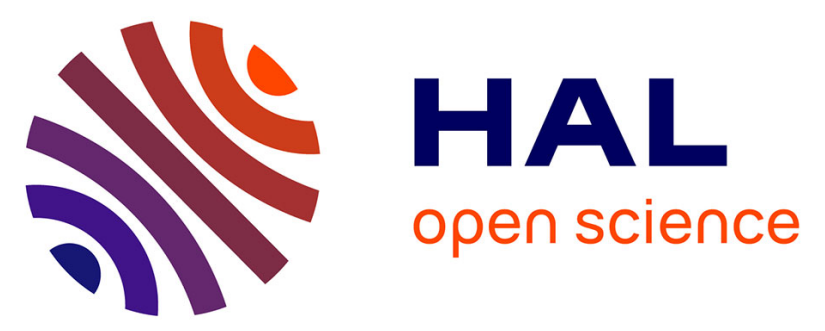

\title{
The 14 November 2001 Kokoxili (Tibet) earthquake: High-frequency seismic radiation originating from the transitions between sub-Rayleigh and supershear rupture velocity regimes
}

\author{
Maxime Vallée, M Landès, Nikolai M. Shapiro, Y Klinger
}

\section{To cite this version:}

Maxime Vallée, M Landès, Nikolai M. Shapiro, Y Klinger. The 14 November 2001 Kokoxili (Tibet) earthquake: High-frequency seismic radiation originating from the transitions between sub-Rayleigh and supershear rupture velocity regimes. Journal of Geophysical Research: Solid Earth, 2008, 113 (B7), pp.B07305. 10.1029/2007JB005520 . insu-01303866

\section{HAL Id: insu-01303866 \\ https://hal-insu.archives-ouvertes.fr/insu-01303866}

Submitted on 18 Apr 2016

HAL is a multi-disciplinary open access archive for the deposit and dissemination of scientific research documents, whether they are published or not. The documents may come from teaching and research institutions in France or abroad, or from public or private research centers.
L'archive ouverte pluridisciplinaire HAL, est destinée au dépôt et à la diffusion de documents scientifiques de niveau recherche, publiés ou non, émanant des établissements d'enseignement et de recherche français ou étrangers, des laboratoires publics ou privés. 


\title{
The 14 November 2001 Kokoxili (Tibet) earthquake: High-frequency seismic radiation originating from the transitions between sub-Rayleigh and supershear rupture velocity regimes
}

\author{
M. Vallée, ${ }^{1}$ M. Landès, ${ }^{2}$ N. M. Shapiro, ${ }^{2}$ and Y. Klinger ${ }^{2}$ \\ Received 23 November 2007; revised 31 March 2008; accepted 5 May 2008; published 24 July 2008.
}

[1] Seismic array based analysis of the major Kokoxili earthquake (Tibet, 14 November 2001) yields an unambiguous reconstruction of the seismic rupture history and relates it to the generated seismic radiation. We demonstrate that after a classical sub-Rayleigh velocity stage, the rupture speed has jumped to supershear values close to compressional wave velocity over a $175-\mathrm{km}$-long fault segment, before abruptly slowing down in the late part of the earthquake. The transition locations between these three phases are correlated with the fault geometry and are associated with the most energetic radiation. This observation proves that the rupture velocity changes, as theoretically predicted, are a primary source of high-frequency seismic radiation. This result requires reconsidering the origins of seismic damage, generally attributed to slip variations.

Citation: Vallée, M., M. Landès, N. M. Shapiro, and Y. Klinger (2008), The 14 November 2001 Kokoxili (Tibet) earthquake: Highfrequency seismic radiation originating from the transitions between sub-Rayleigh and supershear rupture velocity regimes,

J. Geophys. Res., 113, B07305, doi:10.1029/2007JB005520.

\section{Introduction}

[2] Seismic rupture mechanics aims at better understanding of how stresses stored in the Earth are released by earthquakes. When stresses overcome the fault friction, rupture initiates and then propagates with different velocities, depending on the rupture potential energy and fault properties [Andrews, 1976; Day, 1982; Festa and Vilotte, 2006; Dunham, 2007]. It has been theoretically demonstrated in the 1970s [Andrews, 1976] that two rupture velocity modes are possible: either the rupture propagates slower than the Rayleigh velocity (about 0.92 times the shear $(S)$ wave velocity), or between the shear and the compressional $(P)$ velocity. This last regime, called supershear, can exist only if the fault prestress level is high, compared to the failure stress and the residual stress. Moreover fracture energy has to be sufficiently low to permit the development of the supershear phase within the finite length of a real fault [Andrews, 1976; Dunham, 2007].

[3] Rupture supershear propagation does not only provide information about the physical processes leading to earthquakes, but it also strongly modifies the nature of seismic radiation and thus the origins of the damaging waves generated by earthquakes. The most striking difference between supershear and sub-Rayleigh rupture is the presence of an energetic and potentially destructive Mach $S$ wave

\footnotetext{
${ }^{1}$ Géosciences Azur, University of Nice Sophia Antipolis, IRD, CNRS, UPMC, Valbonne, France.

${ }^{2}$ Institut de Physique du Globe de Paris and CNRS, Paris, France.

Copyright 2008 by the American Geophysical Union. 0148-0227/08/2007JB005520\$09.00
}

[Bernard and Baumont, 2005]. Determining if a supershear rupture necessarily implies more devastating effects than a sub-Rayleigh rupture is today an active research area. As a matter of fact, the Mach cone effect could be reduced by a smoother source time function, intrinsically related to the supershear propagation dynamics [Ellsworth et al., 2004; Bizzarri and Spudich, 2008]. Moreover, if the rupture continuously propagates close to an upper limit $(P$ wave velocity), high-frequency radiation related to rupture accelerations and decelerations is reduced. These velocity variations of the rupture front are theoretically known to be a primary source of high-frequency seismic radiation [Madariaga, 1977; Campillo, 1983; Sato, 1994].

[4] Today, it has been shown that both regimes cohabit in laboratory experiments that mimic earthquake rupture [Rosakis et al., 1999]. There is also growing evidence that this may be the case for the real-world events. The first earthquake for which supershear mode has been proposed is the 1979 Imperial Valley earthquake $\left(M_{w}=6.5\right)$ [Archuleta, 1984; Spudich and Cranswick, 1984]. More recent works have shown that this behavior could be more frequent than previously expected: the 1999 Izmit earthquake $\left(M_{w}=7.4\right)$ [Bouchon et al., 2000, 2001], the 1999 Duzce earthquake $\left(M_{w}=7.1\right)$ [Bouchon et al., 2001], the 2001 Kokoxili earthquake $\left(M_{w}=7.8\right)$ [Bouchon and Vallée, 2003; Robinson et al., 2006] and the 2002 Denali earthquake $\left(M_{w}=7.9\right)$ [Ellsworth et al., 2004; Dunham and Archuleta, 2004; Aagaard and Heaton, 2004] all present some indications for supershear rupture. The main weakness of most of these studies, which also explains why the existence of supershear rupture has not been fully accepted, is that rapid rupture velocities are derived from earthquake source inversions, 
affected by some trade-offs between parameters (slip, rupture velocity, risetime) [Beresnev, 2003]. An exception is the early work of Spudich and Cranswick [1984], which provides a more direct observation of the moderate Imperial Valley earthquake by an array technique. Because of the limited information on the supershear regime, and its strong implications in terms of earthquake physics and seismic radiation, scientists have underlined the need of new analyses and observations of rapid rupture velocities [Das, 2007].

[5] In this study, our first goal is to provide a clear observation of the supershear regime. We focus on the 14 November 2001 Kokoxili earthquake, where an array of broad band stations deployed in Nepal allows us to track the rupture propagation, with a similar approach as that of Spudich and Cranswick [1984]. We show that the array configuration, associated with the exceptional length of the event, allows us to well identify a long fault segment where supershear rupture has occurred. We demonstrate that earthquake rupture velocity may even approach the compressional $(P)$ wave velocity. Going further, we put in light the first-order importance that the rupture transition points have on seismic radiation. These points, where rupture accelerates to supershear velocity and then decelerates to the subRayleigh regime, are shown to be localized zones of the fault which emit most of the high-frequency content of the seismic radiation. These localized zones are well correlated with geometrical fault complexities, illustrating the interactions between rupture regimes, seismic radiation and fault geometry.

\section{Array Analysis of the Kokoxili Earthquake 2.1. The 14 November 2001 Kokoxili Earthquake}

[6] On 14 November 2001, the major Kokoxili earthquake $\left(M_{w}=7.8\right)$ struck an arid region in the northern Tibet (Figure 1). This exceptional event ruptured the Kunlun fault, one of the major left-lateral strike-slip faults accommodating the eastward extrusion of Tibet in response to Indian collision [Van der Woerd et al., 2002]. Its rupture length, about $400 \mathrm{~km}$, has made this earthquake the longest inland event ever recorded by digital seismology. Most of the rupture has propagated unilaterally eastward, from the epicenter located at $90.5^{\circ} \mathrm{E}, 35.9^{\circ} \mathrm{N}$ to the beginning of the Kunlun Pass fault at $94.5^{\circ} \mathrm{E}, 35.6^{\circ} \mathrm{N}$ [Klinger et al., 2005; Lasserre et al., 2005; Xu et al., 2006; Klinger et al., 2006]. Classical methods of source process inversion have revealed that the rupture propagation was faster than usually observed, with average velocities ranging between 3.4 and $4.5 \mathrm{~km} / \mathrm{s}$ [Bouchon and Vallée, 2003; Antolik et al., 2004; Ozacar and Beck, 2004; Robinson et al., 2006; Tocheport et al., 2006]. Although these results indicate a likely existence of the supershear regime, some uncertainties have impeded further investigations of the earthquake source process. In particular, the conjoint inversion of slip and rupture velocity does not allow to precisely separate which of the two effects is dominant in terms of seismic radiation.

\subsection{Data and Array Method}

[7] During the Himalayan Nepal Tibet Seismic Experiment (HIMNT), a temporary network of broadband seismometers (Streckeisen STS2) was deployed in Nepal and Tibet in
2001-2003 to study the Himalaya structure [Schulte-Pelkum et al., 2005; Monsalve et al., 2006]. The Kokoxili earthquake, as well as its numerous aftershocks, has been well recorded by a large part of this network. This data set offers a very favorable configuration to track the rupture propagation using array techniques [Krüger and Ohrnberger, 2005; Ishii et al., 2005]. Depending on the location of the radiating points along the Kunlun fault, the time shifts of the radiation arrivals change at the HIMNT stations. The basic idea is to define, at each time of the seismograms, the location of the radiating points that agree the best with the observed time shifts. The formulation of this optimization problem is described as follows. Assuming that the instantaneous source is located at a fault location $x_{i}$, with Rayleigh waves phase velocity through the array $V_{j}$, the family of stacked velocity signals $U_{i j}$ windowed in the interval $\left[t_{0}-T_{w} / 2, t_{0}+T_{w} / 2\right]$ is written as

$$
U_{i j}(t)=\sum_{k=1}^{N} \frac{W_{t_{0}, T_{w}}\left[u_{k}\left(t-\Delta t_{i j k}\right)\right]}{A_{k, t_{0}, T_{w}}}
$$

where the time shift $\Delta t_{i j k}$ is defined as

$$
\Delta t_{i j k}=\left(r_{i 1}-r_{i k}\right) / V_{j}
$$

$W_{t_{0}, T_{w}}$ is the rectangular window function with center $t_{0}$ and width $T_{w}, N$ is the number of stations, $u_{k}$ is the velocity seismogram of station $k$, and $r_{i k}$ is the distance between point located at $x_{i}$ and station $k . A_{k, t_{0}, T_{w}}$ normalizes the amplitude for each seismogram inside each window, with respect to a given reference station. This normalization factor is used to take into account amplitude changes between stations due to different geometrical spreading effects and different radiation amplitudes. The family of stacked energy signals $E_{i j}$, windowed in the interval $\left[t_{0}-\right.$ $\left.T_{w} / 2, t_{0}+T_{w} / 2\right]$ is defined as

$$
E_{i j}(t)=\sum_{k=1}^{N} \frac{W_{t_{0}, T_{w}}\left[u_{k}^{2}\left(t-\Delta t_{i j k}\right)\right]}{A_{k, t_{0}, T_{w}}^{2}}
$$

and the semblance [Neidell and Taner, 1971] in the interval $\left[t_{0}-T_{w} / 2, t_{0}+T_{w} / 2\right]$ is expressed as

$$
S_{i j}=\frac{\int_{t 0-T_{w} / 2}^{t 0+T_{w} / 2} U_{i j}^{2}(t) d t}{N \int_{t 0-T_{w} / 2}^{t 0+T_{w} / 2} E_{i j}(t) d t}
$$

Since the time series $U$ and $\mathrm{E}$ are discrete, discrete sums are used to evaluate $S_{i j}$.

[8] The HIMNT stations are located about $1000 \mathrm{~km}$ from the Kokoxili earthquake. At such distances, Rayleigh surface waves are by far the most energetic signal in the vertical seismograms for a superficial earthquake (see aftershock seismograms in Figure 1). Moreover, aftershock signals show that body waves are complex and not enough separated in time to analyze the 100-s-long duration of the main shock. We therefore apply the array technique to Rayleigh waves recorded at seven stations (Figure 1, see their locations in Table 1) and filtered between $0.04 \mathrm{~Hz}$ and $0.1 \mathrm{~Hz}$ using a two-pass, two-pole, Butterworth filter. Lower 

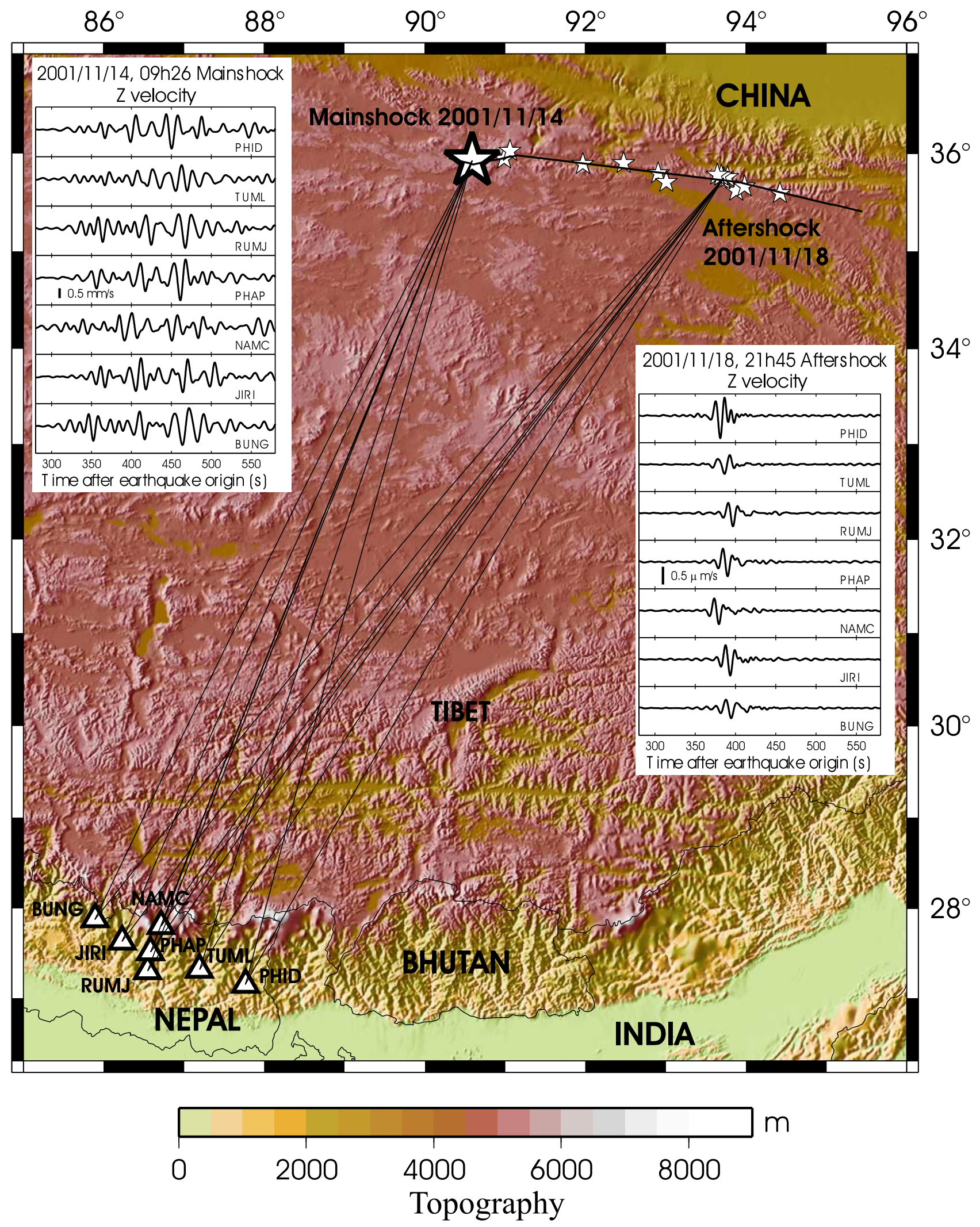

Figure 1. Location of the earthquakes (stars) and the HIMNT seismic stations selected in this study (triangles). The large star shows the main shock epicenter, and the smaller stars indicate the locations of the aftershocks used to estimate array accuracy (Figure 2). Vertical ground motion velocities at the seven stations (filtered between 0.04 and $0.1 \mathrm{~Hz}$ ) are shown both for the main shock (left inset) and for an aftershock (right inset). 
Table 1. Location of the Seven HIMNT Stations Selected in This Study

\begin{tabular}{lccc}
\hline Station & Latitude & Longitude & Elevation $(\mathrm{m})$ \\
\hline PHID & 27.1501 & 87.7645 & 1176 \\
TUML & 27.3208 & 87.1950 & 360 \\
RUMJ & 27.3038 & 86.5482 & 1319 \\
PHAP & 27.5150 & 86.5842 & 2488 \\
NAMC & 27.8027 & 86.7146 & 3523 \\
JIRI & 27.6342 & 86.2303 & 1866 \\
BUNG & 27.8771 & 85.8909 & 1191 \\
\hline
\end{tabular}

frequencies reduce the array resolving power, while higher frequencies have little coherency because of the station separation. $T_{w}$ is taken equal to $25 \mathrm{~s}$, which is longer than the dominant period of the filtered seismograms $(10-15 \mathrm{~s})$. Longer windows would reduce the spatial resolving power. We successively shift $t_{0}$ in steps of $5 \mathrm{~s}$, and calculate for each window the semblance associated with the possible values of $x_{i}$ (along the Kunlun fault trace) and $V_{j}$. The optimal semblance values define the actual fault emission location and phase velocity.

[9] The array analyses are possibly biased by regional crustal heterogeneity which deflects the seismic wavefield (off-great circle propagation). This may cause a discrepancy between the observed arrival direction and the actual station-source azimuth. In order to correct this bias, 14 aftershocks with known locations were analyzed. In this case, the source location does not change when the window moves. Figure 2a shows an example of coherency optimization (in terms of semblance) for one of these aftershocks, which leads to the determination of the source location. Phase velocity and longitude are the only unknowns of this analysis because latitude is constrained by the knowledge of the fault trace [Klinger et al., 2005; Lasserre et al., 2005; Xu et al., 2006; Klinger et al., 2006]. Figure 2b shows the bias between the results of the array analysis and the aftershock locations given by earthquake catalogs based on global wave arrival times. The systematic trend can be corrected by a simple parabolic optimization which is then taken into account when analyzing the main shock rupture propagation.

\section{Origins of the High-Frequency Seismic Radiation}

\subsection{Correlation Between Seismic Radiation and Geometrical Complexities of the Kunlun Fault}

[10] Considering that a curvilinear source along the Kunlun fault is an excellent approximation for the very long shallow Kokoxili earthquake, the array analysis resolves the instantaneous location of the radiating point on the fault. Repeating the analysis over progressive seismogram time windows, we can precisely illuminate the parts of the faults that generated most of the seismic radiation in the investigated frequency band $(0.04-0.1 \mathrm{~Hz})$. Given the global duration of the earthquake (100 s), this frequency range is well beyond the corner frequency and is therefore related to the high-frequency behavior of the earthquake.

[11] Analysis of the time semblance diagram (Figure 3a) reveals four local maxima corresponding to four different emission locations. All array detections over the progressive time windows are reported in Table S1 in the auxiliary material. ${ }^{1}$ The source locations relative to local semblance maxima do not move when the time of the window center varies around the optimal value. This is simply explained considering that semblance analysis identifies an individualized waveform complexity, which is also retrieved for nearby windows integrating this complexity. Locations corresponding to these local maxima represent the four independent location emissions that our analysis is able to accurately resolve. Figures 3b, 3c, 3d, and 3e illustrate the array analysis of these well-resolved high-frequency source emitting points, taking into account the correction deduced from aftershocks.

[12] In order to estimate the uncertainties associated with these determinations, we follow the statistical approach of Fletcher et al. [2006]. We first check that our procedure does not depend on the choice of a reference station. Then we simulate noise-contaminated signals, where the noise is the difference, randomized in phase, between the stacked signal and the real signals at each station. Repeating the semblance analysis over 2000 realizations of the noisecontaminated signals, we define the $95 \%$ location confidence level, which we add in Figure 3. The first emission location ( $\mathrm{P} 0)$ is found close to the rupture epicenter $\left(90.85^{\circ} \mathrm{E}\right)$. Semblance and confidence level are not excellent ( 0.65 and \pm 0.32 , respectively) for $\mathrm{P} 0$, which is likely due to the low radiation of the Rayleigh waves in this direction, close to the nodal plane. Subsequent analysis of Love waves shows that clear energy originates from the epicenter region. The second and third points (P1 and P2) are very clearly defined (semblance is 0.94 and 0.93 , respectively). P1 is located at $92.02^{\circ} \mathrm{E}( \pm 0.1)$ and $\mathrm{P} 2$ at $93.96^{\circ} \mathrm{E}( \pm 0.2)$. The very high semblance at $\mathrm{P} 1$ and $\mathrm{P} 2$ shows that some localized wave emissions occur at these points of the fault. As a matter of fact, extended emissions, on distances longer than the studied wavelengths $(30 \mathrm{~km})$, would reduce the semblance. The last point (P3) is found at the rupture termination $\left(94.5^{\circ} \mathrm{E}\right)$, with a confidence level of \pm 0.27 . Finally, five other points with lower energy and coherency are defined along the Kunlun fault and are represented together with P0, P1, P2, and P3 in Figure 4.

[13] The location of P1 and P2 strongly suggests that the seismic radiation is closely correlated with the rupture geometry. Precise analysis of the surface rupture produced by the Kokoxili earthquake reveals azimuth changes and jogs [Klinger et al., 2005; Xu et al., 2006; Klinger et al., 2006], indicating limits of segments for the coseismic rupture. One of the clearest complexities is the azimuth change of $5.7^{\circ}$ located at $92.05^{\circ} \mathrm{E}$, associated with a large push-up (Figure 5). When the earthquake reaches this geometrical complexity, the rupture transfers from the main localized fault to a myriad of small faults before resuming on the next localized segment [Klinger et al., 2006; King and Nabelek, 1985; King, 1986]. P1 location $\left(92.02^{\circ} \mathrm{E} \pm\right.$ $0.1)$ matches very well this fault feature. Our analysis, based on periods longer than $10 \mathrm{~s}$ (wavelengths larger than about $30 \mathrm{~km}$ ), does not directly prove that this 2-km-long feature is responsible for the emitted radiation. However, if this complexity is the origin of a major rupture propagation

${ }^{1}$ Auxiliary materials are available in the HTML. doi:10.1029/ 2007JB005520. 
a)

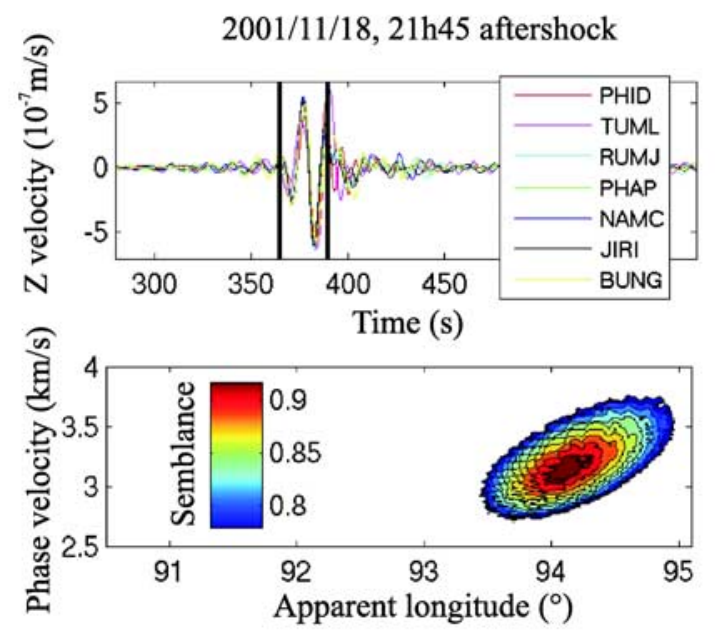

b)

Array analysis accuracy

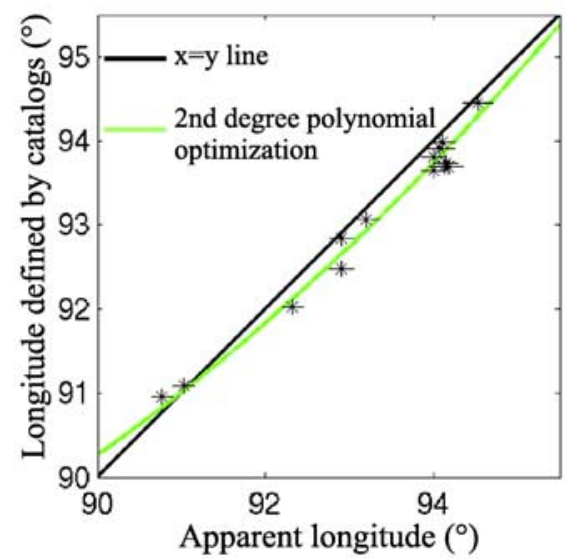

Figure 2. Array analysis of Kokoxili earthquake aftershocks. (a) Example of the 18 November 2001 aftershock. (top) Optimal signal coherency of the seven seismograms. Black thick lines show the 25-s window over which semblance has been computed. (bottom) Semblance sensitivity to fault location (longitude) and to phase velocity. (b) Comparison between longitude defined by array analysis and by earthquake catalogues (National Earthquake Information Center (NEIC), International Seismological Centre, EHB catalog [Engdahl et al., 1998]. Error bars for both location types are shown. A simple second degree polynomial optimization (green curve) corrects for the bias generated by structure complexities deflecting the wavefield.

change, it influences seismic radiation on a large frequency range. Successive analysis shows, for example, that a localized rupture velocity step strongly modifies the seismic radiation for periods between 10 and $25 \mathrm{~s}$. The location of P2 also correlates very well with the largest azimuth change of the fault $\left(7.8^{\circ}\right)$ and, interestingly, with the highest density of aftershocks (Figure 4).

[14] The spatial collocations between the strongest fault complexities and the most energetic radiations indicate that the geometry of the Kunlun fault played an important role in the rupture propagation. However, at this stage, it is not clear if the radiation directly originates from the complexities (for example, change in focal mechanism) or if the complexities were the starting point of different rupture behaviors, which in turn modified the seismic radiation. The subsequent analysis, where a detailed temporal study is added to the spatial radiation distribution, helps us to answer this question.

\subsection{Subshear and Supershear Rupture Velocity Regimes}

[15] Onset times (Ti) associated with fault emission locations $(P i)$ cannot be determined with enough precision from the stacked signals because of the uncertainties related to the width of time window $(25 \mathrm{~s})$. To accurately obtain $T i$, we conjointly use the period-time amplitude diagrams [Levshin et al., 1989] generated by $P i$ and by a nearby aftershock noted $A$. Period-time diagram computed from an aftershock $A$ is used to define, as a function of period $\tau$, group time dispersion curves $D_{A}(\tau)$ for the paths connecting this aftershock and the considered stations [Shapiro et al., 1997]. The next step is to evaluate the group time dispersion curve associated with a subevent $P i$ assuming that there is no significant structural differences between two closely located paths. In this case, we only have to correct for the distance and the dispersion curve $D_{P i}(\tau)$ associated with $P i$, is related to $D_{A}(\tau)$ by

$$
D_{P i}(\tau)=\frac{R_{P i}}{R_{A}} D_{A}(\tau)
$$

where $R_{P i}$ and $R_{A}$ are the distances between the array and $P i$ and the array and $A$, respectively.

[16] We denote by $\operatorname{Ei}(\tau, t)$ the period-time amplitude diagram associated with $P i$. Ti is obtained by maximizing the integral:

$$
L(T)=\int_{D_{P i}(\tau)+T} E i(\tau, t) d l
$$

$L(T)$ simply expresses the amplitude integrated along the dispersion curve shifted by a time delay $T$. Amplitude period-time diagrams associated with $P i$ and aftershocks are computed from corresponding weighted semblance stacks [Kennett, 1987]. This weighted semblance stack is a simple modification of the stack $U_{i j}$ (equation (1)), in which we multiply the stack value at time $t$ by its associated semblance $S_{i j}$, computed over a window centered on $t$. This helps us to isolate energy coming from desired locations. Figure 6 illustrates how this method is able to measure onset time $T 1$ for the subevent P1 using the 21 November 2001 aftershock as reference. To define the uncertainty associated with the measured onset time (44.7 s), we used again noisecontaminated signals (see above for more information about the procedure), both for $P i$ and the aftershock. This shows us that the $95 \%$ time confidence level is $\pm 0.7 \mathrm{~s}$. 
a)

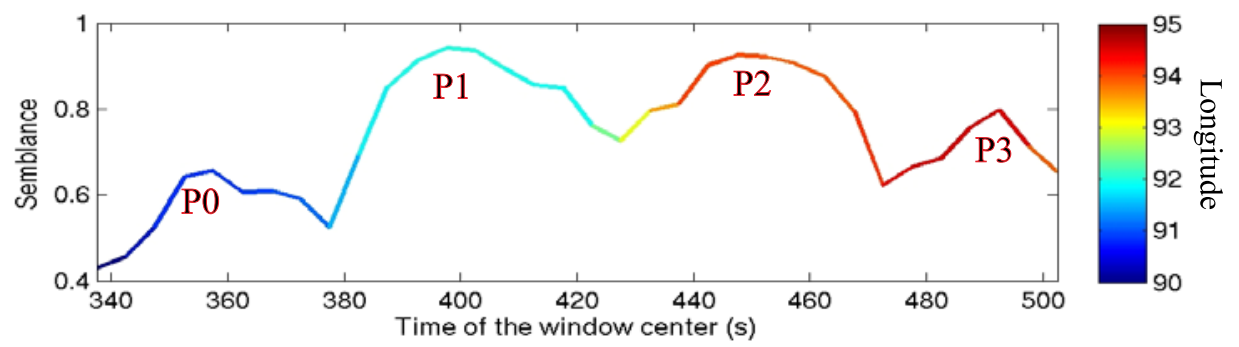

b)
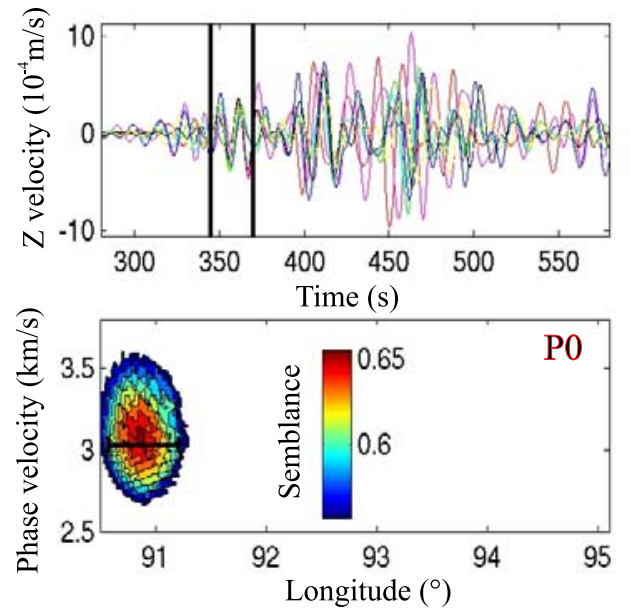

d)
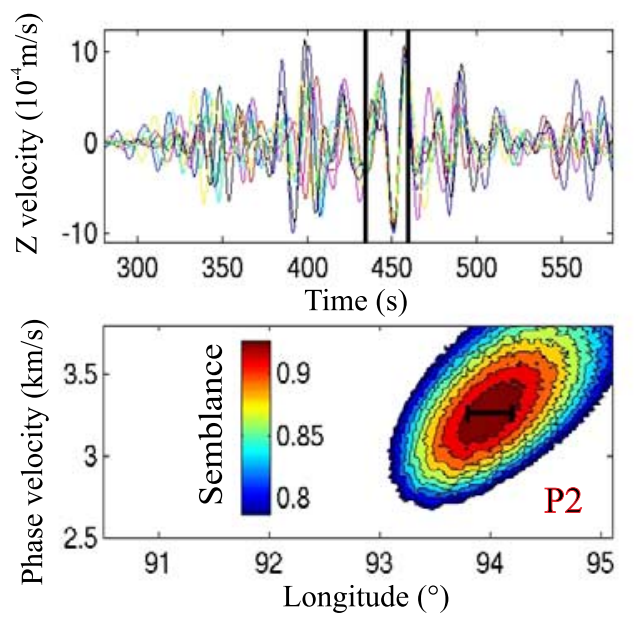

c)

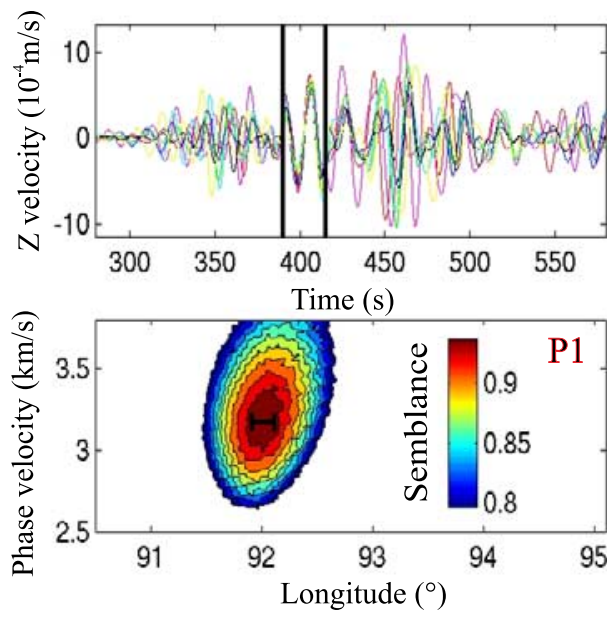

e)
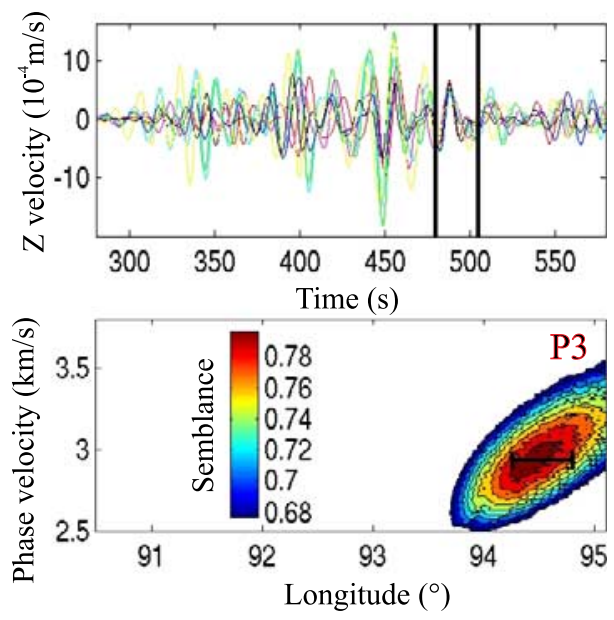

Figure 3. Array analysis of the Kokoxili earthquake Rayleigh waves. (a) Time-semblance diagram of the array analysis. Evolution of semblance over progressive time windows presents four local maxima, relative to the radiating points $\mathrm{P} 0, \mathrm{P} 1, \mathrm{P} 2$ and $\mathrm{P} 3$. Colors are associated with the optimal longitudes defined by the array analysis for each window. (b-e) Detailed analyses related to P0, P1, P2, and P3. See Figure 2a for more details on this location procedure. Note that seismograms in Figures $3 b-3 e$ may look different because of the applied normalization in each window. P0 is found close to the earthquake epicenter, P1 is located at $92.02^{\circ} \mathrm{E}( \pm 0.1), \mathrm{P} 2$ is located at $93.96^{\circ} \mathrm{E}( \pm 0.2)$, and P3 is close to the earthquake termination $\left(94.5^{\circ} \mathrm{E}\right)$ defined by other studies [Lasserre et al., 2005; Xu et al., 2006]. Error bars on longitude (thick horizontal lines) have been defined using a statistical analysis on noisecontaminated signals. 


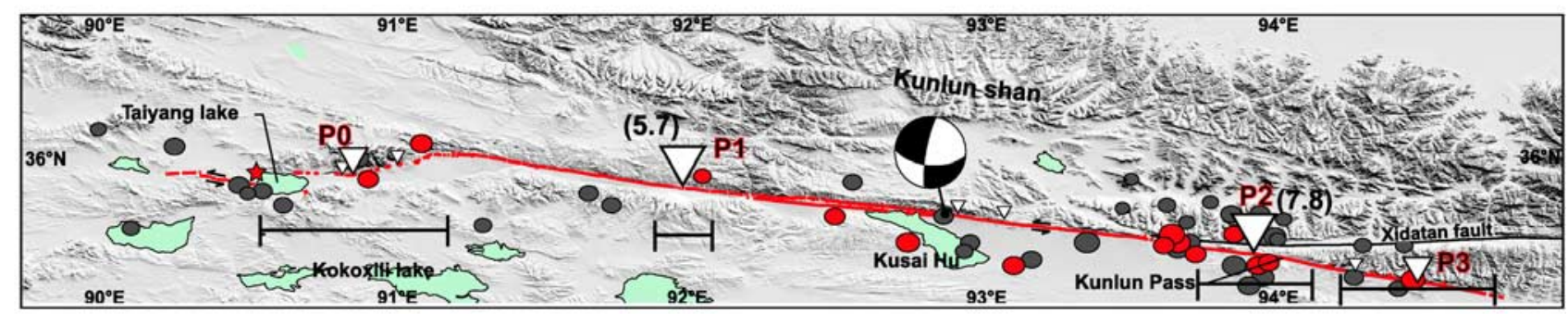

Figure 4. Location map of points imaged by array analysis (triangles, scaled to our level of confidence in the determination). Error bars relative to P0, P1, P2, and P3 are presented below the location of each point. Fault azimuth variations at P1 and P2 are represented as well as the Harvard CMT focal mechanism. Note that a pure vertical left-lateral strike-slip mechanism has been shown to better fit simultaneously surface and body waves [Robinson et al., 2006]. Circles are the 1-year aftershocks of the NEIC catalog, and red circles are the aftershocks used for array calibration (Figure 2).

[17] The global results of the analysis for P1 (two aftershocks) and P2 (five aftershocks) are recorded in Table 2. The measurement is shown to be little dependent on the chosen aftershock. The onset time differences are associated with small errors in aftershock location and origin times, and in the exact location of $P i$. We use the standard deviation of $T 2$ ( $T 1$ has only two measurements, which is not enough to reliably determine standard deviation) as an estimate of this error source. Adding this standard deviation $(0.95 \mathrm{~s})$ to the uncertainty of the measure itself $(0.7 \mathrm{~s})$, the temporal analysis shows that P1 and P2 were activated at $44 \mathrm{~s}$ and $70 \mathrm{~s}$, respectively $( \pm 1.65 \mathrm{~s})$ after the earthquake origin time. The dispersion curves cannot be precisely picked for P0, P3 and some other points identified along the fault (Figure 4). Onset times associated with these radiating points are defined using an average group velocity of $2.94 \mathrm{~km} / \mathrm{s}$ deduced from aftershocks. Gathering the spatial and temporal information, Figure 7 shows the time-distance evolution of the Kokoxili earthquake.

[18] Rupture velocity along the initial $130 \mathrm{~km}$ (before P1) is estimated between 2.7 and $3.3 \mathrm{~km} / \mathrm{s}$, which is close but lower than Rayleigh velocity. Behavior of the Kokoxili earthquake changes abruptly when rupture reaches $\mathrm{P} 1$. The distance between P1 and P2 is $175 \mathrm{~km}( \pm 27 \mathrm{~km})$ and the differential rupture time is $26 \mathrm{~s}( \pm 3.3 \mathrm{~s})$ which implies a rupture velocity between 5.1 and $8.9 \mathrm{~km} / \mathrm{s}$ over this long segment of the Kunlun fault. Taking into account that, theoretically, the rupture velocity cannot exceed the $P$ wave velocity in the shallow crust $(6.5 \mathrm{~km} / \mathrm{s})$, the range of acceptable velocities is reduced to the interval $5.1-6.5 \mathrm{~km} / \mathrm{s}$. This directly shows that rupture velocity may not only be supershear but also very close to the $P$ wave velocity. This behavior, indicated by source inversion methods [Robinson et al., 2006; Bouchon and Vallée, 2003] (Figure 7) and

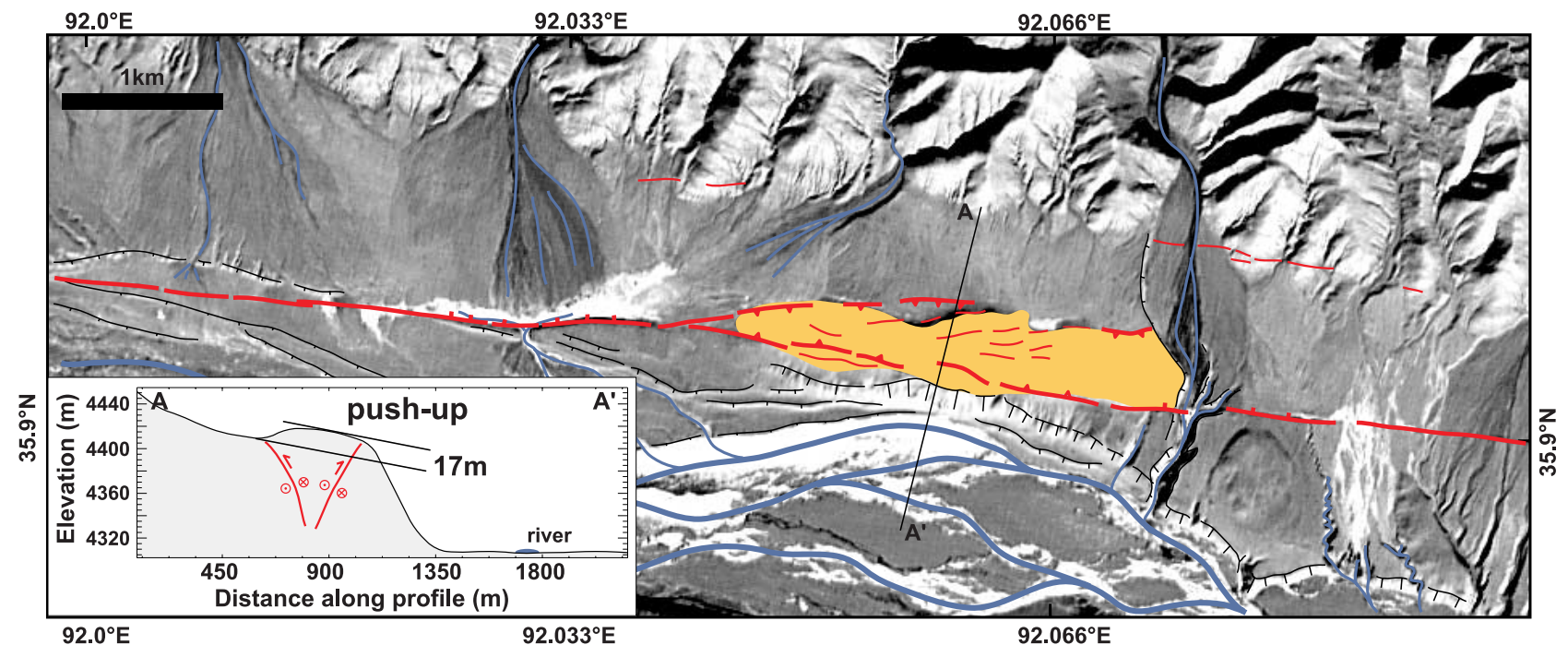

Figure 5. Push-up located along the Kokoxili rupture in $\mathrm{P} 1$, associated with the $5.7^{\circ}$ change in rupture azimuth. Surface rupture associated to the 2001 earthquake, mapped in red, shows both strike-slip motion and thrust on the flanks of the push-up. Rivers are in blue. A-A' topography cross section from SRTM digital elevation model shows elevation of the push-up and position of the main faults according to their surface expression. The total size of the push-up ( $2 \mathrm{~km}$ long, $500 \mathrm{~m}$ wide, $17 \mathrm{~m}$ high) indicates that the compressive jog has been active at least for a couple of earthquake cycles. 
a)

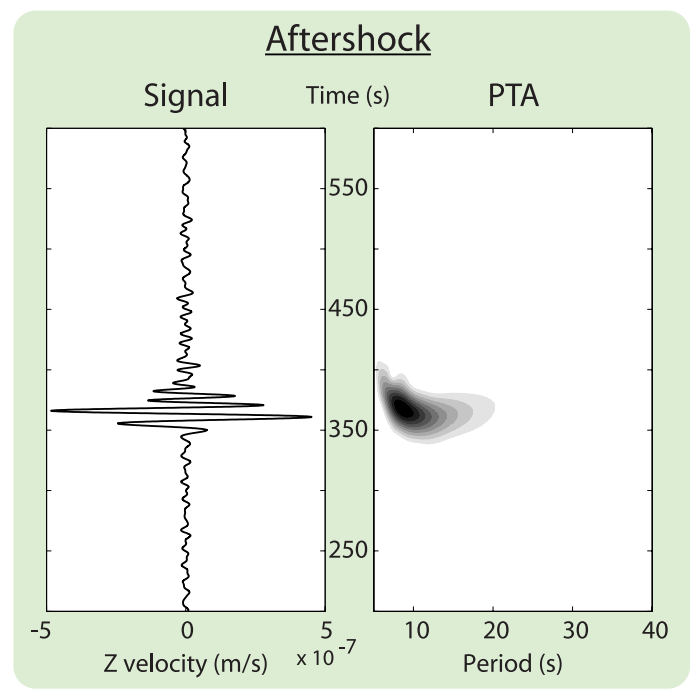

c)

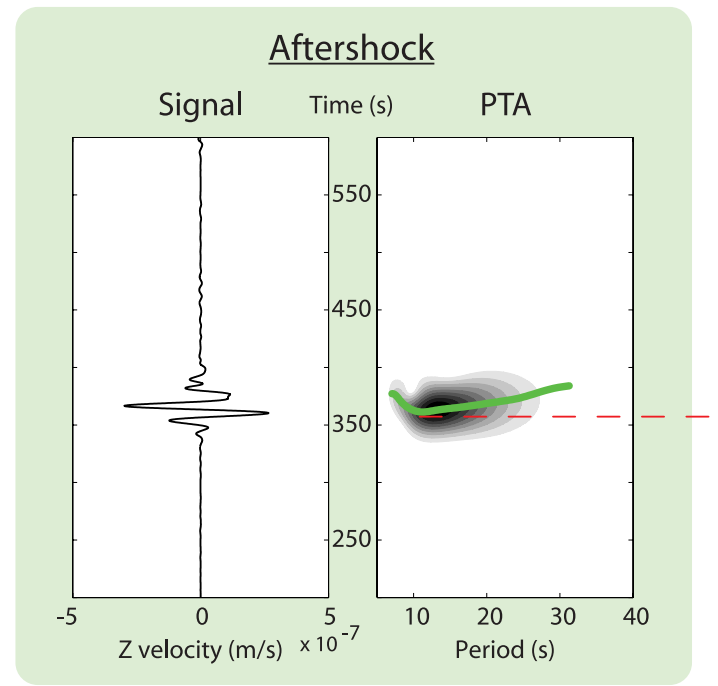

b)

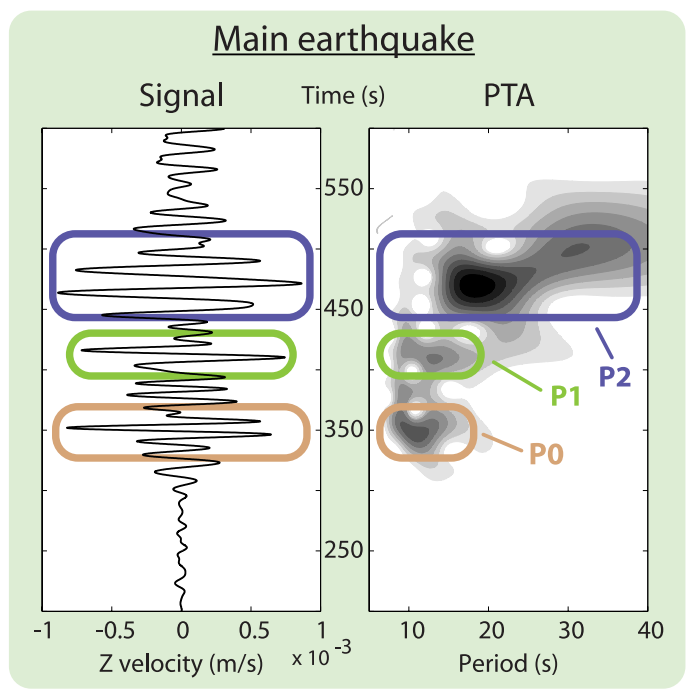

d)

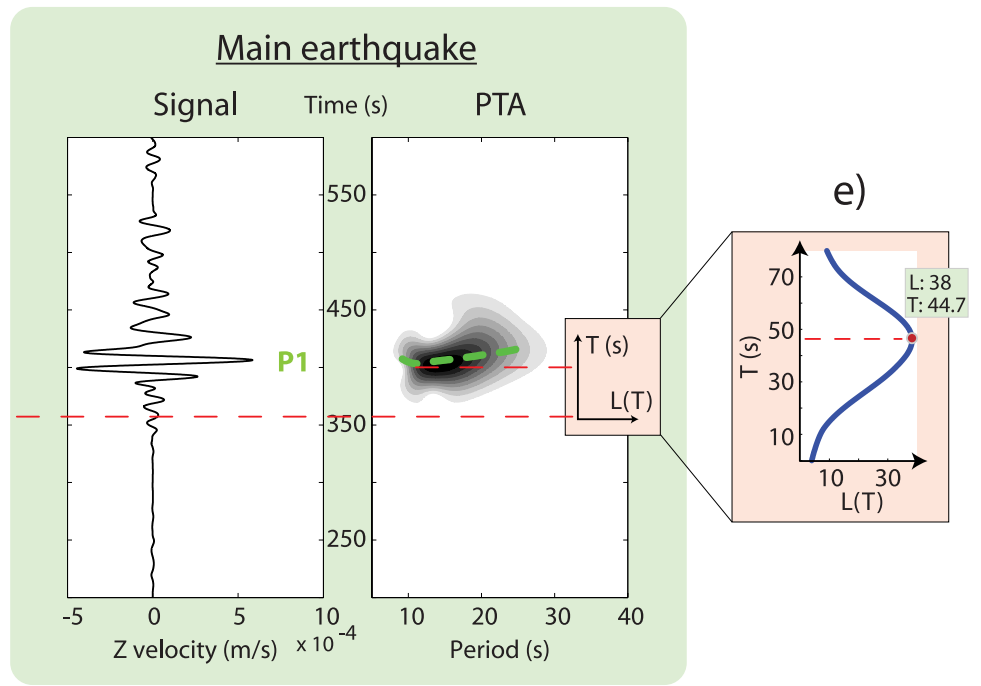

Figure 6. Determination of onset times by dispersion curve analysis. (a) Unfiltered signal and periodtime analysis (PTA) of the ground velocities recorded at BUNG during the 21 November 2001 aftershock. (b) Unfiltered signal and PTA of the ground velocities recorded at BUNG during the main shock. PTA shows three energy bursts related to P0, P1, and P2. P3 cannot be clearly distinguished because it is shadowed by the coda of P2. (c) Weighted semblance stack filtered in 10-25 s period band and PTA of the 21 November 2001 aftershock signals. The dispersion curve (in green) is measured from the PTA. (d) Weighted semblance stack filtered in 10-25 s period band and PTA of the main shock signals. This stack is done using the P1 position and therefore efficiently isolates energy coming from this part of the fault. Figure $6 \mathrm{~d}$ is easier to use than Figure $6 \mathrm{~b}$ because energy associated with $\mathrm{P} 1$ is much better defined. (e) Evolution of $L(T)$, defined in equation (6). This function quantitatively estimates how the dispersion curve of the aftershock should be shifted in time (dashed green line in Figure 6d) to adequately simulate the dispersion curve of the main shock and gives therefore a measure of $\mathrm{T} 1$ (here $44.7 \mathrm{~s}$ ).

predicted by theoretical studies [Andrews, 1976; Day, 1982; Festa and Vilotte, 2006], is here observed during the Kokoxili earthquake.

\subsection{Acceleration and Deceleration Phases}

[19] Existence of strong coherent arrivals clearly identified by the array analysis indicates that the origin of seismic radiation during this earthquake is highly localized. Several factors can be responsible for local energetic radiation: fault mechanism variations, large slip asperities, or rupture velocity changes [Madariaga, 1977; Campillo, 1983; Sato, 1994]. It can be argued that normal or inverse faulting components contaminating the dominant strike-slip mechanism could 
Table 2. Calculation of the Onset Times T1 and T2 With Respect to Different Aftershocks, Using the Method Illustrated in Figure 6

\begin{tabular}{|c|c|c|}
\hline \multirow{2}{*}{$\begin{array}{l}\text { Aftershock Date, } \\
\text { Time (UT) }\end{array}$} & \multicolumn{2}{|c|}{ Onset Time (s) } \\
\hline & $T 1$ & $T 2$ \\
\hline \multicolumn{3}{|c|}{$P 1$} \\
\hline $21 / 11$ & 44.7 & \\
\hline $30 / 11,0500$ & 43.4 & \\
\hline \multicolumn{3}{|c|}{$P 2$} \\
\hline $16 / 11$ & & 70.7 \\
\hline $18 / 11,2145$ & & 69.2 \\
\hline $18 / 11,2200$ & & 68.7 \\
\hline $19 / 11$ & & 71.3 \\
\hline $22 / 11$ & & 70 \\
\hline
\end{tabular}

locally generate stronger Rayleigh waves, responsible for radiation localization.

[20] To check which one of these hypotheses is realistic, we first apply the array analysis to transverse components (Figure 8). Seismograms have been projected along an average transverse direction, where Love surface waves are dominant. As transverse components are noisier for aftershock signals, we do not calibrate the array as we did for Rayleigh waves, but consider that the azimuthal correction remains the same. We have estimated the errors relative to the location emissions by the same statistical analysis conducted for Rayleigh waves. All array detections over the progressive time windows are recorded in Table S2 in the auxiliary material. Figure $8 \mathrm{a}$, analogous to Figure 3a, reveals a similar pattern as the one revealed by Rayleigh waves: the positions L0, L1 and L3, relative to local maxima, match the position of $\mathrm{P} 0, \mathrm{P} 1$ and $\mathrm{P} 2$. L0 is better defined than $\mathrm{P} 0$ and confirms that this phase is emitted very close to the earthquake epicenter. The similarity between Love and Rayleigh wave observations shows that the strong energies emitted at P1 and P2 are not related to fault mechanism changes generating strong Rayleigh waves, but likely originate from a modification in the source process. The timing analysis of $\operatorname{Li}(i=0,3)$ cannot be made precisely as we did for Rayleigh waves. As a matter of fact, the exact transverse direction rotates as the source moves, leading to a contamination of Love waves by Rayleigh waves. However, estimates of the rupture velocity based on an average group velocity and the times of the window center, also imply a supershear behavior in the segment $92^{\circ} \mathrm{E}-94^{\circ} \mathrm{E}$.

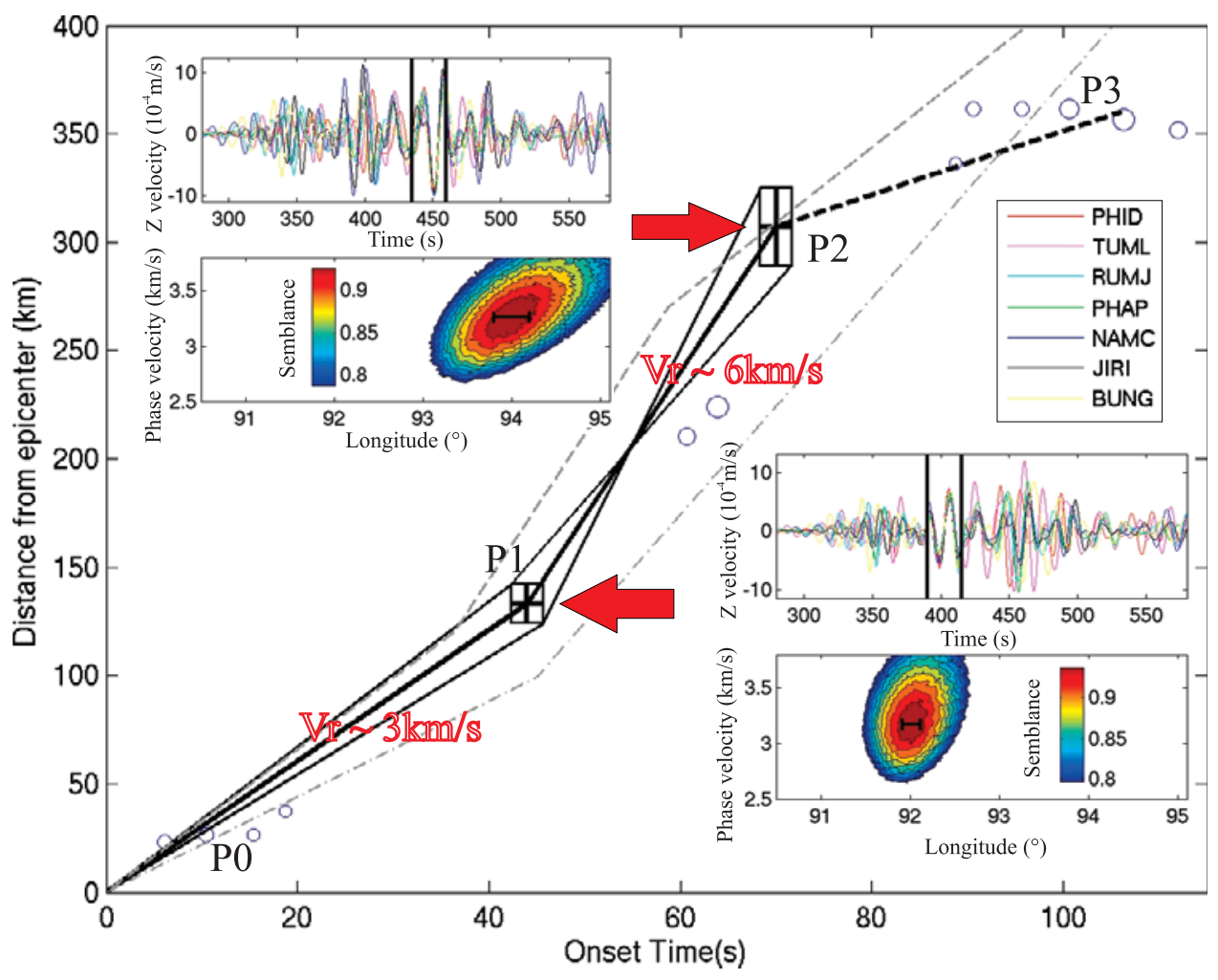

Figure 7. Time-distance evolution of the Kokoxili earthquake. Top left and bottom right insets show the location procedure for the two most coherent time windows corresponding to P1 and P2. Spatial and temporal uncertainties for $\mathrm{P} 1$ and $\mathrm{P} 2$ are represented by crosses in the time-distance diagram. Blue circles, with size proportional to semblance, show other points for which semblance is larger than 0.65 . Since dispersion curves cannot be precisely picked for these points, the onset time is defined by using an average phase velocity of $2.94 \mathrm{~km} / \mathrm{s}$ deduced from aftershocks. This diagram illustrates the three main phases of the Kokoxili earthquake: sub-Rayleigh rupture before P1, supershear rupture between P1 and P2, before returning to classical sub-Rayleigh rupture after P2. As a comparison, rupture velocity behaviors proposed by Bouchon and Vallée [2003] (dashed dotted line) and Robinson et al. [2006] (dashed line) are added. 
a)

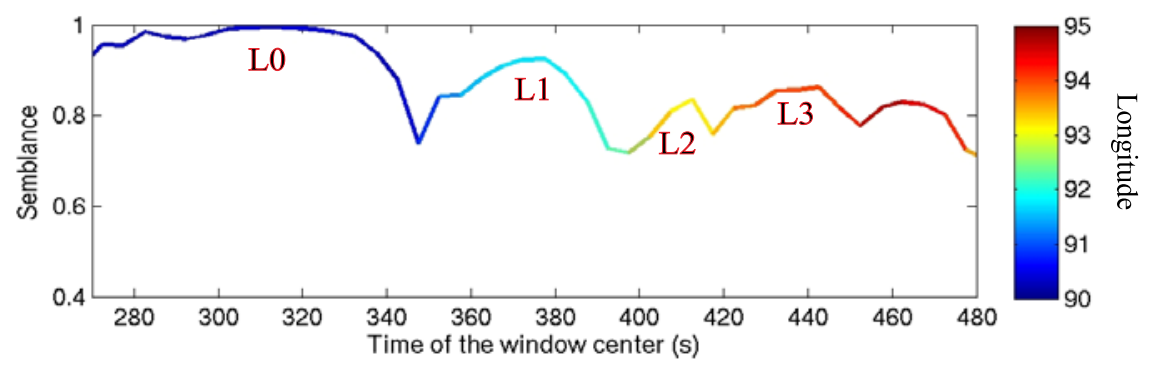

b)
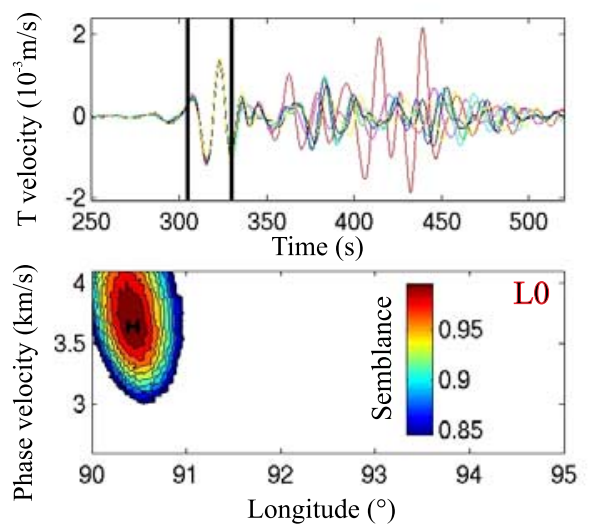

d)

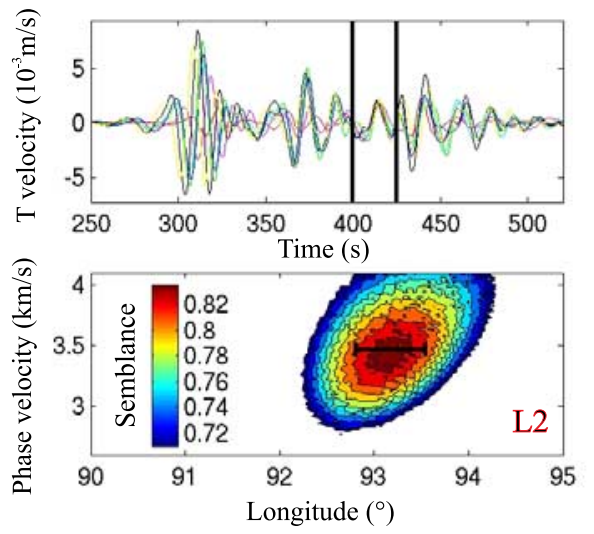

c)
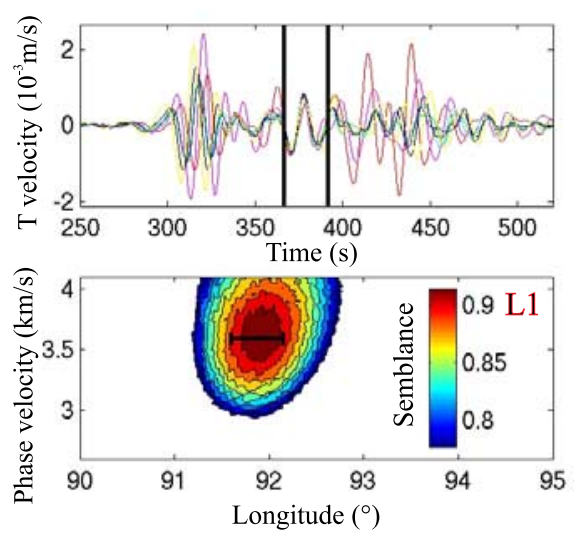

e)

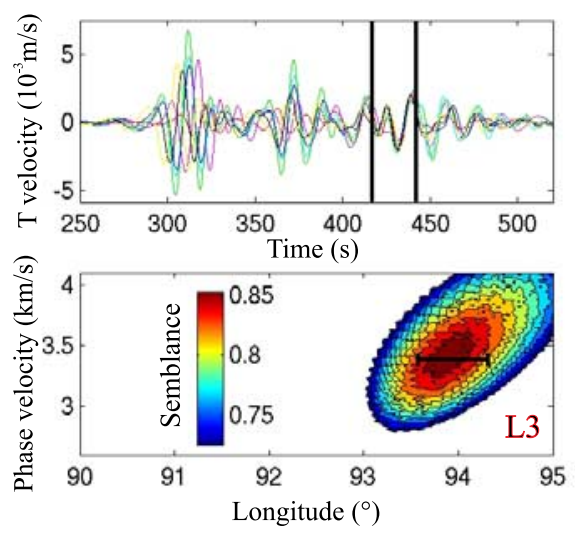

Figure 8. Array analysis of transverse components. Horizontal components have been projected along the azimuth $300^{\circ}$, which is an approximate transverse direction (because of array extension and rupture length). Love waves are therefore dominant on this component. (a) Analogous to Figure 3a. (b-e) Detailed analyses of four local maxima, relative to locations L0, L1, L2, and L3. See Figures 2 a and 3 for more details on the procedure. Similar results as for vertical Rayleigh waves are found (Figure 3): L1 and L3 show energy bursts close to $92^{\circ} \mathrm{E}$ and $94^{\circ} \mathrm{E}$, respectively, corresponding to P1 and P2. L0 images energy close to the epicenter, consistent with P0. L2 is related to a smaller energy burst, located at $93^{\circ} \mathrm{E}$, that has not been well identified by Rayleigh waves.

[21] The hypothesis of the asperity generated radiation is also unlikely because locations of strongly radiating parts on fault are poorly correlated with maximum slip. The largest surface breaks (Figure 9b), as well as the largest slip imaged by interferometric synthetic aperture radar (INSAR) [Lasserre et al., 2005], occurred in the segment between $92.6^{\circ} \mathrm{E}$ and $93.5^{\circ} \mathrm{E}$. Therefore, rupture velocity changes imaged by the array are very likely themselves the cause of strong seismic radiation. To validate this assumption, we simulated seismic waveforms using a onedimensional propagation medium deduced from the aftershock seismograms (Figure 10). Synthetic seismograms have been computed [Bouchon, 1981] using a pure leftlateral strike-slip mechanism following the Kunlun fault geometry. The kinematic model only considers the rupture velocity changes derived from array analysis (Figure 9c). 

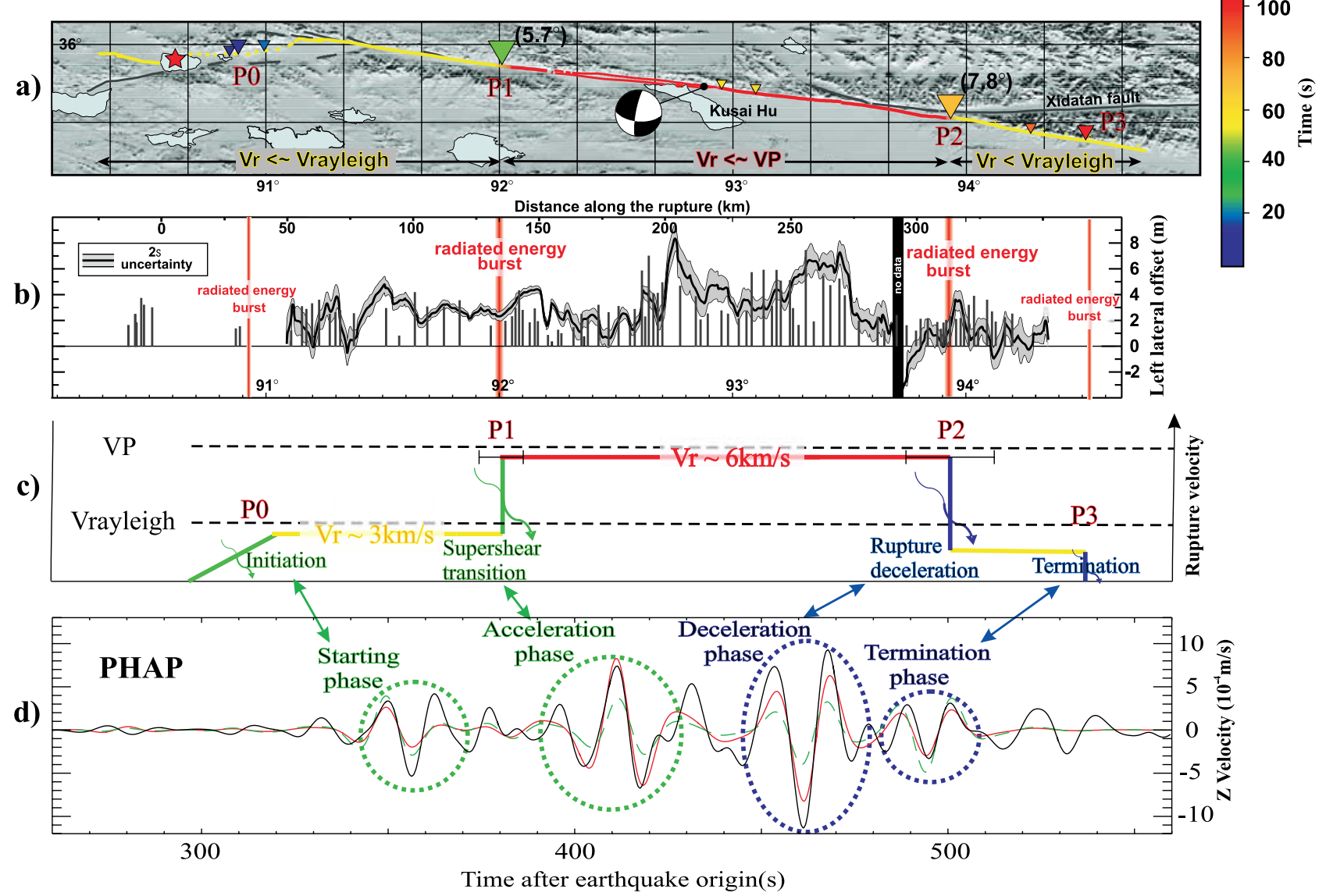

Figure 9. Rupture properties and seismic radiation of the Kokoxili earthquake. (a) Location map of points imaged by array analysis (triangles, scaled to our level of confidence in the determination). Colors are associated with onset times. Inferred rupture velocity regimes and azimuth variations at P1 and P2 are represented. (b) Comparison of energetic radiation locations with surface slip distribution deduced from optical correlation [Klinger et al., 2006] (average values are shown with a black line and the shadowed area indicates the uncertainties) and field observation [Xu et al., 2006] (shown with vertical bars). Little radiated energy is associated with the largest slip segment between $92.6^{\circ} \mathrm{E}$ and $93.5^{\circ} \mathrm{E}$. Slip distributions inferred from other data, for example, INSAR analysis [Lasserre et al., 2005], are very similar and do not show large slip in the high-frequency radiation areas. (c) Rupture velocity scheme of the Kokoxili earthquake deduced from array analysis. Location uncertainties for P1 and P2 are indicated. (d) This kinematic behavior is employed to simulate seismograms at PHAP, using a crustal structure deduced from aftershock waveform fitting (Figure 10). Two simple slip distributions are considered, relative to model 1 and model 2 defined in the text. Synthetics for model 1(dashed green) and 2 (red) are in good agreement with the data (black) complexity in the $0.04-0.1 \mathrm{~Hz}$ frequency band, showing that seismic radiation is directly related to acceleration and deceleration phases. Model 2 better explains the data amplitudes, suggesting that supershear rupture is associated with a larger slip.

We have considered two slip functions: the first one is a uniform slip model (model 1), whereas the second one assumes that slip is twice larger in the supershear region (model 2), which schematically models the detailed surface displacement (Figure 9b). Compared to the uniform model, model 2 only modulates the amplitude of the seismic radiation, but does not change the shape of the radiation complexity. The resulting synthetic seismograms related to model 1 (dashed green curve) and to model 2 (red curve) are presented in Figure 9d. Both models well explain the radiation complexity, showing that the wavefield is well described in terms of acceleration and deceleration phases.
This last observation also indicates that the rupture was continuously supershear between P1 and P2, and that the observed radiation at P2 is not due to a triggered event ahead of the wavefront. As a matter of fact, such a process would generate an acceleration phase at P2, with an opposite polarity, and would not explain the seismograms. Model 2 better reproduces the seismogram amplitudes, suggesting that the supershear regime is associated with a larger slip.

[22] This analysis shows that rupture accelerations and decelerations have a first-order effect on the high-frequency seismic radiation, which is consistent with theoretical results 

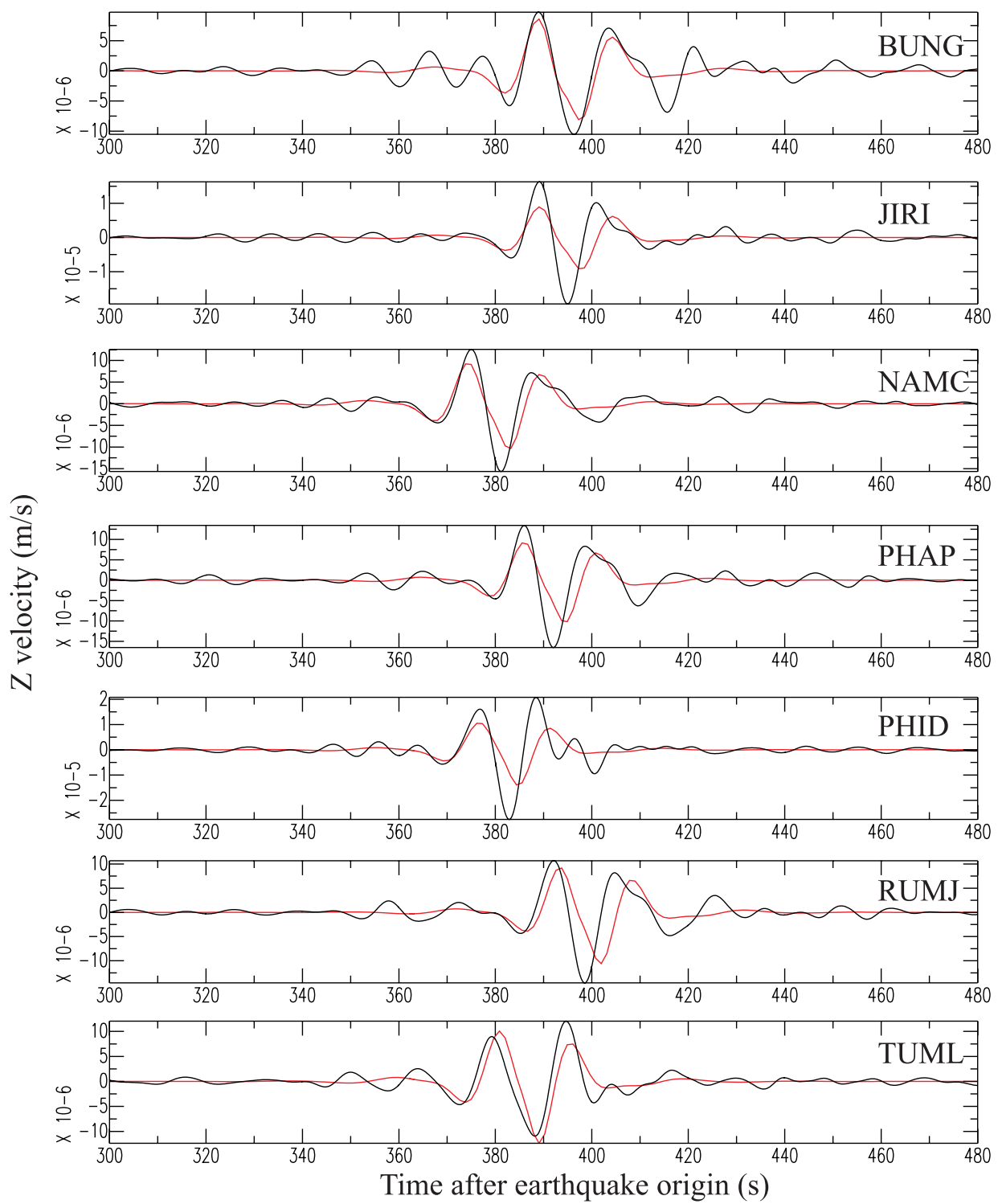

2001/11/18, 22h aftershock

strike, dip, rake $=280^{\circ}, 40^{\circ}, 112^{\circ}$

depth $=3.5 \mathrm{~km}$

$\mathrm{Mw}=5.5$

Half space structure $(\mathrm{Vp}, \mathrm{Vs}$, density,Qp,Qs $)=(5.45 \mathrm{~km} / \mathrm{s}, 3.15 \mathrm{~km} / \mathrm{s}, 2700 \mathrm{~kg} / \mathrm{m} 3,600,300)$

Figure 10. Waveform modeling of the 18 November 2001 (2200 UT) aftershock. Using a focal mechanism consistent with Harvard CMT, associated with a simple velocity structure (presented at the bottom), Rayleigh surface waves of this aftershock are shown to be well modeled. Synthetics (red) and data (black) are band-pass-filtered between 0.04 and $0.1 \mathrm{~Hz}$. The velocity structure is used to model the main shock waveforms in Figure 9d.

[Madariaga, 1977; Campillo, 1983; Sato, 1994]. The location of acceleration and deceleration phases governs the radiation complexity and slip variations only modulate the seismogram amplitudes. These observations have interesting consequences for the seismic source understanding. In terms of source analysis, the usual hypothesis that strong high-frequency radiation is associated with strong slip variations has to be reconsidered. In terms of seismic risk, it implies that the most damaged zones should be close to the rupture front irregularities rather than to the large slip areas.

\section{Discussion and Conclusions}

[23] The presented observations of the Kokoxili earthquake should help to fill a gap between theoretical and observational rupture seismology. We have directly put in light the relations between rupture propagation, fault com- 
plexity, and high-frequency seismic radiation. We show that the earthquake initiation is associated with a first highfrequency seismic radiation (P0). Between $\mathrm{P} 0$ and $\mathrm{P} 1$, the rupture propagates with a classical subshear rupture velocity $(\sim 3 \mathrm{~km} / \mathrm{s})$. When the rupture arrives at P1, $130 \mathrm{~km}$ after its initiation, it brutally accelerates and approaches the $P$ wave velocity $(\sim 6 \mathrm{~km} / \mathrm{s})$. This extreme rupture velocity, which has been inferred by indirect inversion techniques, is here directly observed by the array analysis. The abrupt regime change at P1 generates strong high-frequency radiation as predicted by theoretical and numerical studies [Madariaga, 1977; Campillo, 1983; Sato, 1994]. Once the supershear regime is established, between $\mathrm{P} 1$ and $\mathrm{P} 2$, little highfrequency radiation is emitted, as expected for a steady propagation. $175 \mathrm{~km}$ after $\mathrm{P} 1$, the rupture decelerates at $\mathrm{P} 2$, which is the origin of another high-frequency phase. This emission location is well correlated with the highest density of aftershocks, suggesting that the end of the supershear regime is a zone of complex stress reorganization. Finally, the rupture dies $50 \mathrm{~km}$ farther at $\mathrm{P} 3$, generating a last highfrequency radiation.

[24] The rupture velocity regimes are interestingly correlated with fault geometry. Beginning a few kilometers after $\mathrm{P} 1$, between $92.2^{\circ} \mathrm{E}$ and $92.9^{\circ} \mathrm{E}$, the rupture is partitioned between the main strike-slip fault and an auxiliary normal fault [King et al., 2005]. This could be understood because mode III rupture (here dip slip) cannot theoretically propagate at supershear speeds. Development of an auxiliary sub-Rayleigh fault would allow the accommodation of this slip component away from the strike-slip supershear segment. P1 and P2 themselves, the transition points where the rupture accelerates and decelerates, are not ordinary points of the Kunlun fault. P1 is a complex transition zone between two well localized fault segments with different azimuths (Figure 5). When the earthquake reaches this geometrical complexity, the rupture transfers from the main localized fault to a myriad of small faults before resuming on the next localized segment. Such a variation in the rupture propagation is likely to generate acceleration and deceleration phases, consistent with the collocation of P1. We can infer that when rupture arrives at P1, with a well established subRayleigh velocity, a small modification of the fault properties may drive the rupture to the supershear regime. Moreover, the azimuth change at P1 (5.7 $7^{\circ}$ toward the extensional side of the fault) modifies the stress on the fault, and it has been experimentally and theoretically shown [Rousseau and Rosakis, 2003; Bhat et al., 2004] that the rupture is generally promoted in this case. We propose that the conjoint effects of well established rupture, of a geometrical complexity, and of a favorable modification of the stress have driven the rupture to the supershear regime. At P2, the opposite effect occurs. The rupture encounters the strongest azimuth change of the fault $\left(7.8^{\circ}\right)$, which orients the subsequent rupture toward the compressional side. Moreover, the rupture propagates after P2 on an auxiliary fault with a larger inverse component, which impedes the supershear propagation.

[25] Our study not only shows that the acceleration and deceleration phases related to P1 and P2 exist, but also that they are the dominant signals of the seismograms. We demonstrate that the waveforms are very well explained by a simple rupture velocity model, where rupture velocity jumps to $6 \mathrm{~km} / \mathrm{s}$ at P1, before decreasing at P2, and stopping at P3. Slip variations only have a second-order influence, modulating the radiation amplitude but not its shape. This finding has important implications in terms of earthquake source process inversion, classically conducted since the works of Olson and Apsel [1982] and Hartzell and Heaton [1983]. This last approach deduces from the seismic radiation the slip, rupture velocity and risetime on the fault. Contrary to our array analysis, where we can extract rupture velocity independently from the slip, these two parameters are retrieved conjointly in source inversion methods. A certain level of coupling between slip and rupture velocity has lead most studies to preferentially invert for slip, constraining or fixing the values of the rupture velocity. This assumption is generally argued by the fact that a number of earthquakes tends to have rupture velocity of the order of $80 \%$ of the shear velocity [e.g., Heaton, 1990]. Our results imply that this choice should be reconsidered, because rupture velocity may exhibit significant variations that result in strong radiation, at least when short periods (i.e., shorter than the source duration) are analyzed.

[26] Finally, the influence of the rupture velocity on the seismic radiation has important consequences for seismic scenarios of strong ground motion. These scenarios generally consider that the complexity of the high-frequency seismic radiation is closely related to the complexity of the static slip on the fault. This is, for example, the main idea of the initial $k^{2}$ model [Herrero and Bernard, 1994; Bernard et al., 1996]. Our observation of the Kokoxili earthquake implies that the role of the rupture velocity should be enhanced, as proposed by Hisada [2000, 2001]. The radiation complexity would be linked to the complex variations of the rupture velocity, generating acceleration and deceleration phases, while the slip would only modulate this radiation. We have shown here that the array analysis of the Kokoxili earthquake provides information at a broad scale, from the mechanics of the earthquake rupture to the origins of strong ground motion generation. It should help a better understanding and modeling of the complex interaction between fault geometry, rupture properties and seismic radiation.

[27] Acknowledgments. We are grateful to Anne Sheehan, HIMNT experiment, and IRIS for easy access to the data. This work has benefited from very constructive reviews provided by Paul Spudich and an anonymous reviewer. We thank Pascal Bernard, Michel Bouchon, Cécile Lasserre, Jean Virieux, Pascal Favreau, Stéphane Gaffet, and Shamita Das for fruitful discussions. Comments by Matthew Yedlin, Jean-Mathieu Nocquet, and Christopher Wibberley have improved the initial manuscript.

\section{References}

Aagaard, B. T., and T. H. Heaton (2004), Near-source ground motions from simulations of substained intersonic and supersonic fault ruptures, Bull. Seismol. Soc. Am., 94, 2064-2078.

Andrews, D. J. (1976), Rupture velocity of plane strain shear cracks, J. Geophys. Res., 81, 5679-5687.

Antolik, M., R. E. Abercrombie, and G. Ekström (2004), The 14 November 2001 Kokoxili (Kunlunshan), Tibet, earthquake: Rupture transfer through a large extensional step-over, Bull. Seismol. Soc. Am., 94, 1173-1194.

Archuleta, R. J. (1984), A faulting model for the 1979 Imperial Valley earthquake, J. Geophys. Res., 89, 4559-4585.

Beresnev, I. A. (2003), Uncertainties in finite-fault slip inversions: To what extent to believe? (A critical review), Bull. Seismol. Soc. Am., 93, 24452458 . 
Bernard, P., and D. Baumont (2005), Shear Mach wave characterization for kinematic fault rupture models with constant supershear rupture velocity, Geophys. J. Int., 162, 431-447, doi:10.1111/j.1365-246X.2005.02611.x.

Bernard, P., A. Herrero, and C. Berge (1996), Modeling directivity of heterogeneous earthquake ruptures, Bull. Seismol. Soc. Am., 86, 11491160.

Bhat, H. S., R. Dmowska, J. R. Rice, and N. Kame (2004), Dynamic slip transfer from the Denali to Totschunda faults, Alaska: Testing theory for fault branching, Bull. Seismol. Soc. Am., 94, S202-S213.

Bizzarri, A., and P. Spudich (2008), Effects of supershear rupture speed on the high-frequency content of $\mathrm{S}$ waves investigated using spontaneous dynamic rupture models and isochrone theory, J. Geophys. Res., 113 B05304, doi:10.1029/2007JB005146.

Bouchon, M. (1981), A simple method to calculate Green's functions for an elastic layered medium, Bull. Seismol. Soc. Am., 71, 959-971.

Bouchon, M., and M. Vallée (2003), Observation of long supershear rupture during the magnitude 8.1 Kunlunshan earthquake, Science, 301, $824-$ 826, doi:10.1126/science. 1086832 .

Bouchon, M., N. Toksoz, H. Karabulut, M. P. Bouin, M. Dietrich, M. Aktar, and M. Edie (2000), Seismic imaging of the 1999 Izmit (Turkey) rupture inferred from the near-fault recordings, Geophys. Res. Lett., 27, 30133016.

Bouchon, M., M. P. Bouin, H. Karabulut, M. N. Toksoz, M. Dietrich, and A. J. Rosakis (2001), How fast is rupture during an earthquake? New insights from the 1999 Turkey earthquakes, Geophys. Res. Lett., 28 , $2723-2726$

Campillo, M. (1983), Numerical evaluation of the near-field high-frequency radiation from quasidynamic circular faults, Bull. Seismol. Soc. Am., 73 , $723-734$.

Das, S. (2007), The need to study speed, Science, 317, 889-890, doi: $10.1126 /$ science. 1142143

Day, S. M. (1982), Three-dimensional simulation of spontaneous rupture: the effect of nonuniform prestress, Bull. Seismol. Soc. Am., 72, 18811902.

Dunham, E. M. (2007), Conditions governing the occurrence of supershear ruptures under slip-weakening friction, J. Geophys. Res., 112, B07302, doi:10.1029/2006JB004717

Dunham, E. M., and R. J. Archuleta (2004), Evidence for a supershear transient during the 2002 Denali fault earthquake, Bull. Seismol. Soc. Am., 94, S256-S268.

Ellsworth, W. L., M. Celebi, J. R. Evans, E. G. Jensen, M. C. Metz, D. J. Nyman, J. W. Roddick, P. Spudich, and C. D. Stephens (2004), Near-field ground motions of the $M 7.9$ November 3, 2002, Denali fault, Alaska, earthquake recorded at pump station 10, Earthquake Spectra, 20, 597 615

Engdahl, E. R., R. van der Hilst, and R. Buland (1998), Global teleseismic earthquake relocation with improved travel times and procedures for depth determination, Bull. Seismol. Soc. Am., 88, $722-743$.

Festa, G., and J.-P. Vilotte (2006), Influence of the rupture initiation on the intersonic transition: Crack-like versus pulse-like modes, Geophys. Res. Lett., 33, L15320, doi:10.1029/2006GL026378.

Fletcher, J. B., P. Heaton, and L. M. Baker (2006), Rupture propagation of the 2004 Parkfield, California, earthquake from observations at the UPSAR, Bull. Seismol. Soc. Am., 96, S129-S142.

Hartzell, S. H., and T. H. Heaton (1983), Inversion of strong ground motion and teleseismic waveform data for the fault rupture history of the 1979 Imperial Valley, California earthquake, Bull. Seismol. Soc. Am., 73 $1553-1583$.

Heaton, T. H. (1990), Evidence for and implications of self-healing pulses of slip in earthquake rupture, Phys. Earth Planet. Inter., 64, 1-20.

Herrero, A., and P. Bernard (1994), A kinematic self-similar rupture process for earthquakes, Bull. Seismol. Soc. Am., 84, 1216-1228.

Hisada, Y. (2000), A theoretical omega-square model considering the spatial variation in slip and rupture velocity, Bull. Seismol. Soc. Am., 90, $387-400$.

Hisada, Y. (2001), A theoretical omega-square model considering spatial variation in slip and rupture velocity; part 2, Case for a two-dimensional source model, Bull. Seismol. Soc. Am., 91, 651-666.

Ishii, M., P. M. Shearer, H. Houston, and J. E. Vidale (2005), Rupture extent, duration, and speed of the 2004 Sumatra-Andaman earthquake imaged by the Hi-Net array, Nature, 435, 933-936, doi:10.1038/nature03675.

Kennett, B. L. N. (1987), Observational and theoretical constraints on crustal and upper mantle heterogeneity, Phys. Earth Planet. Inter., 47 $319-332$.

King, G. C. (1986), Speculations on the geometry of the initiation and termination processes of earthquake rupture and its relation to morphology and geological structures, Pure Appl. Geophys., 124, 567-585.

King, G. C., and J. Nabelek (1985), The role of fault bends in faults in the initiation and termination of earthquake rupture, Science, 283, 984-987.
King, G., Y. Klinger, D. Bowman, and P. Tapponnier (2005), Slip partitioned surface breaks for the 2001 Kokoxili earthquake, China $\left(M_{w} 7.8\right)$, Bull. Seismol. Soc. Am., 95, 731-738

Klinger, Y., X. Xu, P. Tapponnier, J. Van der Woerd, C. Lasserre, and G. King (2005), High-resolution satellite imagery mapping of the surface rupture and slip distribution of the $M_{w} \sim 7.8$, November 14, 2001 Kokoxili earthquake (Kunlun fault, northern Tibet, China), Bull. Seismol. Soc. Am., 95, $1970-1987$.

Klinger, Y., R. Michel, and G. King (2006), Evidence for a barrier model from $M_{w} 7.8$ Kokoxili (Tibet) earthquake slip-distribution, Earth Planet. Sci. Lett., 242, 354-364.

Krüger, F., and M. Ohrnberger (2005), Tracking the rupture of the $M_{w}=9.3$ Sumatra earthquake over $1,150 \mathrm{~km}$ at teleseismic distance, Nature, 435, 937-939, doi:10.1038/nature03696.

Lasserre, C., G. Peltzer, F. Crampé, Y. Klinger, J. Van der Woerd, and P. Tapponnier (2005), Coseismic deformation of the $2001 M_{w}=7.8$ Kokoxili earthquake in Tibet, measured by synthetic aperture radar interferometry, J. Geophys. Res., 110, B12408, doi:10.1029/2004JB003500.

Levshin, A. L., T. B. Yanovskaya, A. V. Lander, B. G. Bukchin, M. P. Barmin, L. I. Ratnikova, and E. N. Its (1989), Recording, identification, and measurement of surface wave parameters, in Seismic Surface Waves in a Laterally Inhomogeneous Earth, edited by V. I. Keilis-Borok, pp. $131-$ 182, Kluwer Publ., Dordrecht, Netherlands.

Madariaga, R. (1977), High-frequency radiation from crack (stress drop) models of earthquake faulting, Geophys. J. R. Astron. Soc., 51, 625-651. Monsalve, G., A. Sheehan, V. Schulte-Pelkum, S. Rajaure, M. R. Pandey, and F. Wu (2006), Seismicity and one-dimenstional velocity structure of the Himalayan collision zone: Earthquakes in the crust and upper mantle, J. Geophys. Res., 111, B10301, doi:10.1029/2005JB004062.

Neidell, N., and M. T. Taner (1971), Semblance and other coherency measures for multichannel data, Geophysics, 36, 482-497.

Olson, A. H., and R. J. Apsel (1982), Finite faults and inverse-theory with applications to the 1979 Imperial Valley earthquake, Bull. Seismol. Soc. Am., 72, 1969-2001

Ozacar, A. A., and S. L. Beck (2004), The 2002 Denali fault and 2001 Kunlun fault earthquakes: Complex Rupture Processes of Two Large Strike-Slip Events, Bull. Seism. Soc. Am., 94, S278-S292.

Robinson, D. P., C. Brough, and S. Das (2006), The $M_{w}$. 7.8, 2001 Kunlunshan earthquake: Extreme rupture speed variability and effect of fault geometry, J. Geophys. Res., 111, B08303, doi:10.1029/2005JB004137.

Rosakis, A. J., O. Samudrala, and D. Coker (1999), Cracks faster than shear wave speed, Science, 284, 1337-1340.

Rousseau, C., and A. J. Rosakis (2003), On the influence of fault bends on the growth of sub-Rayleigh and intersonic dynamic shear ruptures, J. Geophys. Res., 108(B9), 2411, doi:10.1029/2002JB002310.

Sato, T. (1994), Seismic radiation from circular cracks growing at variable rupture velocity, Bull. Seism. Soc. Am., 84, 1199-1215.

Schulte-Pelkum, V., G. Monsalve, A. Sheehan, M. R. Pandey, S. Sapkota, R. Bilham, and F. Wu (2005), Imaging the Indian subcontinent beneath the Himalaya, Nature, 435, 1222-1225, 30 June 2005-doi:10.1038/ nature 03678 .

Shapiro, N. M., M. Campillo, A. Paul, S. K. Singh, D. Jongmans, and F. J. Sanchez-Sesma (1997), Surface wave propagation across the Mexican Volcanic Belt and the origin of the long-period sesimic wave amplification in the valley of Mexico, Geophys. J. Int., 128, 151-166.

Spudich, P., and E. Cranswick (1984), Direct observation of rupture propagation during the 1979 Imperial Valley earthquake using a short baseline accelerometer array, Bull. Seismol. Soc. Am., 74, 2083-2114.

Tocheport, A., L. Rivera, and J. Van der Woerd (2006), A study of the 14 November 2001 Kokoxili earthquake: History and geometry of the rupture from teleseismic data and field observations, Bull. Seismol. Soc. Am., 96, 1729-1741

Van der Woerd, J., P. Tapponnier, F. J. Ryerson, A. S. Meriaux, B. Meyer, Y. Gaudemer, R. C. Finkel, M. W. Caffee, G. G. Zhao, and Z. Q. Xu (2002), Uniform postglacial slip-rate along the central $600 \mathrm{~km}$ of the Kunlun fault (Tibet), from Al-26, Be-10, and C-14 dating of riser offsets, and climatic origin of the regional morphology, Geophys. J. Int., 148 , $356-388$.

Xu, X., G. Yu, Y. Klinger, P. Tapponnier, and J. Van Der Woerd (2006), Reevaluation of surface rupture parameters and faulting segmentation of the 2001 Kunlunshan earthquake $\left(M_{w} 7.8\right)$, northern Tibetan Plateau, China, J. Geophys. Res., 111, B05316, doi:10.1029/2004JB003488.

Y. Klinger, M. Landès, and N. M. Shapiro, Institut de Physique du Globe de Paris, 4 place Jussieu, F-75252 Paris CEDEX 05, France. (klinger@ipgp jussieu.fr; landes@ipgp.jussieu.fr; nshapiro@ipgp.jussieu.fr)

M. Vallée, Géosciences Azur, 250 avenue Albert Einstein, F-06560 Valbonne, France. (vallee@geoazur.unice.fr) 